\title{
Alguns trabalhos em madeira dos índios Kashuiéna*
}

\author{
Gottfried Polykrates
}

POLYKRATES, G. Alguns trabalhos em madeira dos índios Kashuiéna. R. Museu Arq. Etn. 37: 61-65, 2021.

Resumo: Neste artigo, originalmente publicado na revista Folk em 1960, Polykrates chama a atenção para a fabricação de objetos em madeira entalhada por parte dos então nomeados Kashuiéna (Katxuyana), objetos que o autor teria encontrado em uma aldeia às margens do rio Cachorro durante as visitas que fez àquele local (em 1957 e 1958). A partir de suas observações sobre um bastão cerimonial e duas tabuletas com acessórios - segundo ele, para aspirar substâncias alucinógenas -, neste texto, Polykrates apresenta descrições e fotos de tais objetos e chama atenção para a importância de seu registro e aquisição pelo Museu Nacional de Copenhagen (Dinamarca), evitando-se assim o risco de perda desses artefatos por eventual desuso por parte dos Katxuyana.

Palavras-chave: Cultura material; Artefato em madeira; Objeto ritual; Katxuyana; Paricá.

$\mathrm{N}^{\circ}$ o verão de 1957, durante a minha visita aos índios Kashuiéna, que vivem às margens do rio Cachorro, um dos afluentes da margem direita do rio Trombetas, no estado do Pará (Polykrates 1957), descobri algumas antigas peças entalhadas em madeira, de muito boa qualidade. Já naquela época tentei obter uma peça de propriedade do chefe da tribo, porém, sem sucesso.

No ano seguinte, participei da segunda expedição dinamarquesa Guiana-Brasil. Acompanhei o sr. Jens Yde, do Museu Nacional da Dinamarca, em Copenhague, na travessia pela Guiana Britânica e pelo estado do Pará até o rio Amazonas, e tive a oportunidade de visitar novamente, por um breve período, os índios Kashuiéna. Fiquei muito contente em constatar que ainda havia os objetos mencionados e que continuavam em perfeito estado.

* Tradução: Marcelo Victor.
Trata-se de um bastão cerimonial e de duas tabuletas com acessórios para aspirar substâncias alucinógenas. Eu não vi o bastão em uso, mas as tabuletas (Fig. 1), sim durante a chamada festa Kurínguri (Polykrates 1957: 144146). De acordo com o chefe da tribo, o bastão de cerimônias é raramente usado, apenas em cerimônias em que a tribo Kashuiéna toda esteja presente, o que, porém, não acontece há muito tempo. A provável razão para isso é que a tribo está dividida em aldeias muito distantes umas das outras.

O bastão (Fig. 5) recebe o nome de jiwáraua e é composto por três partes. A superior é entalhada em madeira e, na língua kashuiéna, tem o nome de uochtsáraka. Infelizmente não pude identificar a espécie da planta em que a peça foi esculpida.

A parte central é composta por ossos de onça-pintada (Panthera onca), kaiksú, e a parte inferior de madeira de tucum (Astrocaryum sp.; A. jauari), jauára. 
A peça compõe-se, como se pode observar na figura 5 , de uma escultura simbolizando dois animais. Acima, um urubu-rei (Sarcoramphus papa), um kurúmu sentado, que se transforma em uma jiboia (Boa constrictor), ou tshikarakái. Visto que o animal aqui representado tem orelhas, é possível que o escultor tenha tido a intenção ou de retratar outro animal, diferente daquele que os índios Kashuiéna me descreveram como uma cobra, ou mesmo um animal lendário.

Os ossos de onça foram talhados em formas cilíndricas. No vão que atravessa o osso, as partes superior e inferior do bastão foram desbastadas e encaixadas.

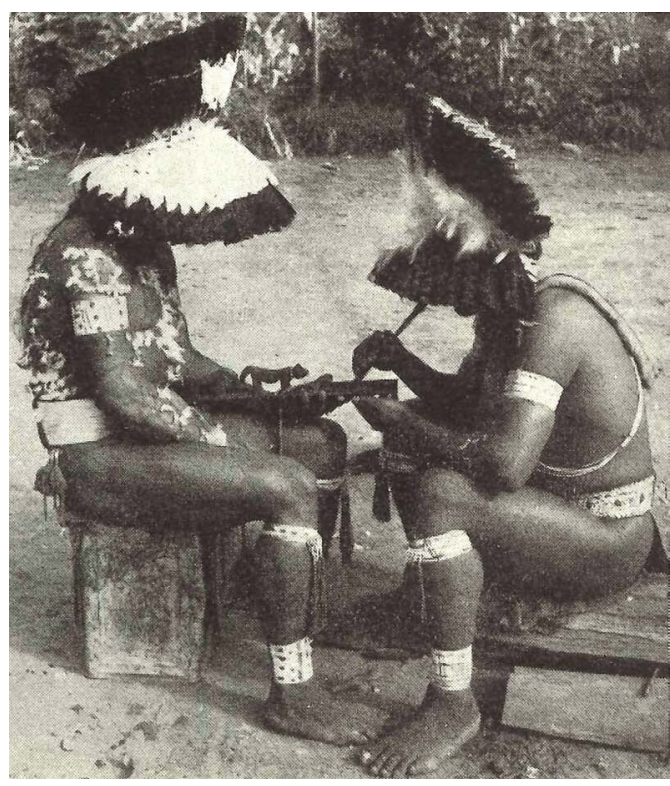

Fig. 1. Índios Kashuiéna inalando.

Fonte: Elaborada pelo autor (1957).

As partes em madeira são de um marrom muito escuro, que converge para a cor preta, com riscas vermelhas em alguns pontos. A tinta que confere a essas partes a cor marrom escuro recebe o nome de pianojaúmu. Dentre os Kashuiéna, entendese que o artesão assim fez como se fazia em seu tempo, no que se pode reconhecer um traço de tradição. Os Kashuiéna de hoje repintaram-nas há alguns anos.
A tinta é composta de uma mistura de casca de ingá (Inga sp.), kurámi, raspada e triturada, água (túna) e urucum (Bixa orellana), onómto, assim como fuligem, erumat'. A fuligem é obtida pela queima de resina, uéju, por meio do seguinte processo: a resina é inflamada sob uma panela com um buraco para a circulação de ar e posta com o bocal para baixo. O buraco é, então, coberto com uma pequena tigela, e a fumaça passa a produzir a fuligem.

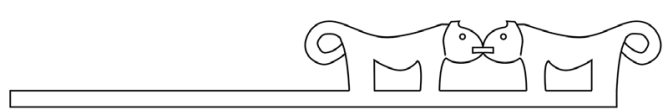

Fig. 2. Tabuleta com os animais de frente um para o outro. Comprimento: $40 \mathrm{~cm}$; altura: $6,5 \mathrm{~cm}$; espessura: $2 \mathrm{~cm}$.

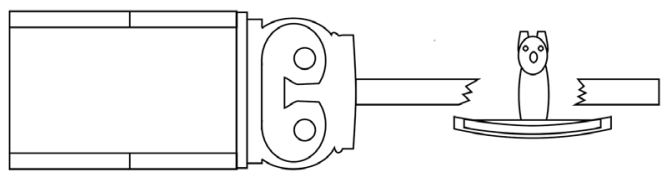

Fig. 3. Face superior de ambas as tabuletas.

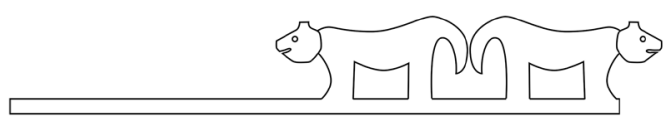

Fig. 4. Tabuleta com os animais de costas um para o outro. Comprimento: $45 \mathrm{~cm}$; altura: $6,5 \mathrm{~cm}$; espessura: 2,1 cm; ambas as tabuletas têm $9,5 \mathrm{~cm}$ de largura.

Para os ornamentos feitos de pontos e traços, foram usados pigmentos de sorvagrande (Couma macrocarpa), osochkú. A tinta não é nada mais do que a seiva avermelhada da planta. Alega-se que o suco do amapádoce (Hancornia amapa), conhecido em kashuiéna por jamá, produz o mesmo pigmento avermelhado.

Esse bastão cerimonial é considerado sagrado pela tribo e é sempre manuseado com grande cuidado e respeito. Há um cesto 
feito especialmente para esse fim, onde esses objetos ficam depositados e postos sob vigília na "casa dos homens". Sempre que eu as tomava em minhas mãos para medilas e para desenhá-las, havia comigo um pajé que tomava cuidado para que eu não as danificasse.

A sacralidade, se posso usar aqui esse termo, está na importância do urubu-rei na mitologia Kashuiéna: conta-se que, há centenas de anos, a ave morreu e sua alma vive ao lado de Purá (a entidade mais elevada dos Kashuiéna). Seus descendentes, os atuais kurumús, mantêm contato com ela a fim de auxiliar os Kashuiéna em qualquer situação. Os curandeiros podem convocá-los em suas cerimônias.

As tabuletas (Fig. 2, 3 e 4) também recebem o nome de jiwáraua e teriam sido feitas na mesma época, entalhadas em madeira uochtsáraka. Elas têm a mesma cor que o bastão cerimonial e são tratadas com os mesmos pigmentos.

Como mostram as ilustrações, cada tabuleta é composta por uma tábua que tem dois animais esculpidos como alça. Sobre uma das tabuletas (Fig. 2), os animais estão de frente; sobre a outra (Fig. 4), estão de costas um para o outro.

Os animais esculpidos de frente um para o outro são chamados de jára. Contase que são duas onças aquáticas cujas patas dianteiras têm membranas e se assemelham às de lontras, enquanto as patas traseiras são patas de onça. Esses animais são considerados os mais perigosos dentre os que existem em rios e florestas. Seus rugidos podem ser ouvidos com muita frequência à noite, embora ninguém nunca os tenha visto. Aqui gostaria de acrescentar que os "caboclos" brasileiros relatam com grande reverência um animal lendário semelhante, o qual, embora tenha as patas traseiras de cavalo, tem as mesmas características. Também nesse caso foi impossível encontrar alguém que tenha visto esse animal.

Os animais da outra tabuleta (Fig. 4), de costas um para o outro, devem ser onçaspintadas, chamadas kaiksú pelos Kashuiéna.

Os animais esculpidos na superfície da tabuleta, semelhantes a uma coruja (Fig. 3), devem ter função apenas decorativa. Eles não pretendem representar nenhum animal e não têm nome algum. Nas duas depressões arredondadas feitas no lugar dos olhos (que aqui comparo aos de uma coruja), estão dispostas duas lâminas de alumínio. É provável que, em tempos antigos, fossem postas conchas limadas, as quais, após se soltarem e desaparecerem, foram substituídas pelo alumínio.

Visto que a coruja desempenha papel fundamental na mitologia Kashuiéna e o entalhe feito na superfície da tabuleta indica uma semelhança bastante perceptível com uma coruja, é provável que o artesão do entalhe tenha, de início, pretendido retratar uma coruja.

Os ornamentos em forma de traços e pontos na face inferior das tabuletas (Fig. 8) também não recebem nome, e os Kashuiéna não lhe atribuem um significado imagético. Também percebi que não são atribuídos nomes aos padrões de decoração em outros trabalhos.

Também compõem a tabuleta canudos duplos (Fig. 6), que recebem o nome uitshóko e são feitos de uma espécie de gramínea chamada tistíkami (Panicum horizontale). $\mathrm{Na}$ extremidade superior, portanto, a parte a ser posta nas narinas, são guarnecidos por dois diferentes frutinhos com um furo atravessando seu centro. Os frutinhos claros, que têm cor avermelhada, sua cor natural, são chamados máriha e são frutos da palmeira inajá (Maximiliana regia). Os outros, de cor preta, auéke, são frutos de mumbaca (Astrocaryum mumbaca Mart.). 
Alguns trabalhos em madeira dos índios Kashuiéna

R. Museu Arq. Etn., 37: 61-65, 2021.

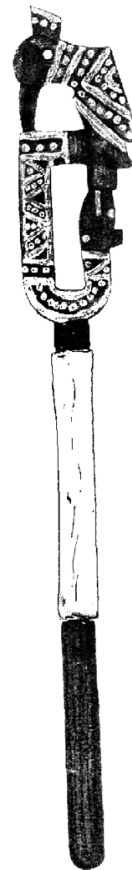

Fig. 5. Bastão cerimonial. Comprimento: $49,5 \mathrm{~cm}$; largura máxima: $6,5 \mathrm{~cm}$; espessura: $2,1 \mathrm{~cm}$; diâmetro do osso: $2,3 \mathrm{~cm}$; comprimento do osso: $15,5 \mathrm{~cm}$.

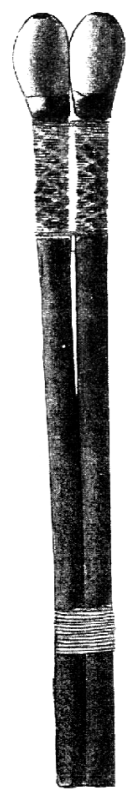

Fig. 6. Canudos. Comprimento total: $22,5 \mathrm{~cm}$; diâmetro: $9 \mathrm{~mm}$; comprimento de cada um dos frutos: $3 \mathrm{~cm}$; largura: $1,7 \mathrm{~cm}$.

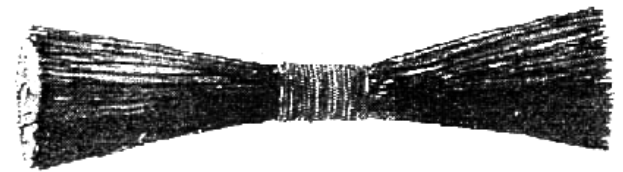

Fig. 7. Escova. Comprimento: $10 \mathrm{~cm}$; espessura no centro: $1 \mathrm{~cm}$.

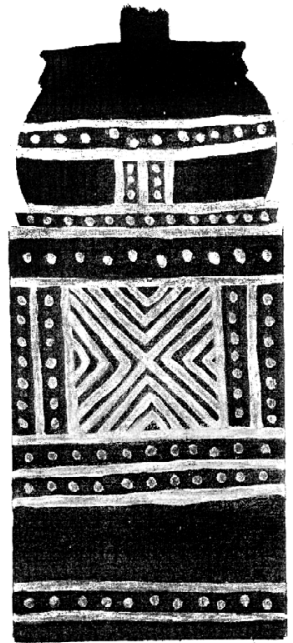

Fig. 8. Face inferior das tabuletas.

Os canudos estão presos um ao outro por maúru, algodão, tanto na parte superior quanto na inferior. Nesta, o fio de algodão envolve os canudos em grossas paralelas; na superior, o trançado é feito em forma de cruz. Entre os canudos e os frutos é usado maní, resina de anani (Symphonia globulifera L.), para vedação.

Os canudinhos são pintados de preto com a seiva de mamunáthe, jacarandá (Machaerium lunatum L., Drepanocarpus ferox Mart.), à qual são adicionadas água e fuligem.

Por fim, também compõe a tabuleta uma escova dupla, de $10 \mathrm{~cm}$ de comprimento e $1 \mathrm{~cm}$ de diâmetro (Fig. 7), feita de pelos de tamanduábandeira (Myrmecophaga tridactyla) ligados no meio por fios de algodão. Essa escovinha recebe o nome de uému.

É difícil determinar a idade das peças descritas acima. No entanto, pode-se dizer com segurança que são de tempos antigos. Não é necessário chamar a atenção para o seu valor e sua raridade: a rara ocorrência de trabalhos 
com madeira entre indígenas que habitam as florestas, ainda mais de tamanha qualidade, pode determinar o valor dessas peças.

Pode-se afirmar com segurança que os objetos descritos acima passaram por três gerações, pois se sabe que o pai do atual chefe os recebeu de seu pai. Posso arriscar comparar seu delicado trabalho artístico, assim como seu estilo e possivelmente a elevada idade, às peças expostas no Museu Nacional de Copenhague e nos museus de Lleida, Viena e Londres.

Resta-nos esperar que outra expedição consiga obter essas peças antes que elas caiam em mãos erradas, pereçam com o avançado processo de civilização dos Kashuiéna ou que se percam de alguma outra forma.

POLYKRATES, G. Some woodwork by the Kashuiéna people. R. Museu Arq. Etn. 37: 61-65, 2021.

Abstract: In this article, published in 1960 in the Folk journal, Polykrates highlights the wood carvings crafted by the then-called Kashuiéna people (Katxuyana), found by the author in a village on the Cachorro riverbanks during his visits (in 1957 and 1958). Polykrates describes and presents pictures of a ceremonial stick and two tablets with accessories - according to him, to aspirate hallucinogenic substances, - stressing the importance of recording these artifacts and their acquisition by the National Museum of Denmark, thus avoiding the risk of loss due to eventual disuse by the Kashuiéna.

Keywords: Material culture; Wooden artifact; Ritual object; Katxuyana; Paricá.

\section{Referências bibliográficas}

Polykrates, G. 1957. Ein besuch bei Indianern am Rio

Trombetas. Ethnos 22: 128-147. 